\title{
Proteolytic Activity of Aspergillus niger Strains Isolated from Soil
}

\author{
Wael Shehada ${ }^{1,4 *}$, Güven Uraz ${ }^{1}$, Rasime Demirel ${ }^{2}$ and Haluk Hamamci ${ }^{3}$ \\ ${ }^{1}$ Gazi University, Faculty of Science, Department of Biology, Ankara, Turkey \\ ${ }^{2}$ Eskişehir Technical University, Faculty of Science, Department of Biology, Eskisehir, Turkey \\ ${ }^{3}$ Middle East Technical University, Faculty of Engineering, Department of Food Engineering, \\ Ankara, Turkey \\ ${ }^{4}$ The Islamic University of Gaza, Faculty of Science, Department of Biology and \\ Biotechnology, Gaza, Palestine \\ *Corresponding author
}

\section{A B S T R A C T}

\section{Keywords}

Aspergillus niger, Protease activity, Calcium Caseinate Agar, Skim Milk Agar, Fermentation, sequencing

\section{Article Info}

Accepted:

10 January 2021

Available Online:

10 February 2021
This study was proposed to determine the recovery rate of Aspergillus species in Ankara, Turkey, from soil and their identification as well as to evaluate the proteolytic activity of the isolated strains. 20 different soil samples were collected and searched for the presence of the fungal species after selective plating and internal transcribed spacer (ITS) gene region sequencing of cPCR fragments. Also it was the first report to screen the biologically active peptides production from the recovered Aspergillus isolates by plate assay method using two agar media including Calcium Caseinate and Skim Milk Agar with different $\mathrm{pH}$ values. In addition to the activity of Aspergillus protease as crude extracted enzyme obtained by fermentation was determined using agar well diffusion method. Overall, 9 (45\%) samples were morphologically proposed as positive fungal isolates and only six of them $(66,7 \%)$ were sequenced and identified as Aspergillus nigerwith recovery rate of $30 \%(6 / 20)$. These six A. niger isolates were allocated in the NCBI GenBank Database and assigned GQ229076.1, EU314995.1, GQ229076.1, GQ229076.1, GQ229076.1 and GQ229076.1 accession numbers. The proteolytic activity of the extracted enzyme on Calcium Caseinate Agar of A. niger isolates was high and showed wide clearance zone of 10,16 and $20 \mathrm{~mm}$ diameter at $\mathrm{pH} \mathrm{5,6.6}$ and 7.3 respectively in compared to that of a reference A. niger strain ATCC 16404 which was only 8, 12 and $14 \mathrm{~mm}$ at same $\mathrm{pH}$.The current proteolytic activity showed qualitative documented results at different $\mathrm{PH}$. Consequently, the acid and alkaline protease activities of A. niger isolates were confirmed. Using Calcium Caseinate and Skim Milk Agar allowed the efficient trial for Aspergillus peptides production and activity creating large scale production of it.

\section{Introduction}

Proteases are one of the most important groups of enzymes that play an important role in various industries (60\% share) such as food, textiles, leather, de-hairing, photos, cheese-making, detergents, pharmaceutical and feed (Zambare et al., 2011 and Nirmal et 
al., 2011). Proteases occur in all organisms in both Prokaryotes and eukaryotes. Bacteria secrete proteases to hydrolyse the peptide bonds in proteins and therefore break the proteins down into their constituent amino acids. Bacterial and fungal proteases are particularly important to the global carbon and nitrogen cycles in the recycling of proteins, and such activity tends to be regulated by nutritional signals in these organisms (Sims, 2006). Fungal proteases have attracted the attention of environmental biotechnologists because fungi can grow on low cost substrates and secrete large amount of enzymes into culture medium which could ease downstream processing (Anitha and Palanivelu, 2013). In recent years, fungal protease production has gained significance and different fungal strains can secret various extracellular hydrolytic enzymes such as amylases, lipases and proteases (Nirmal et al., 2011 and Souza et al., 2015). Proteases have been classified on the basis of their acid/base properties into three groups acidic, neutral and alkaline proteases. The acidic proteases are those which have their $\mathrm{pH}$ optimum in the range of 2.0 to 5.0 and have mainly fungal origin. The proteases having their $\mathrm{pH}$ optimum at 7.1 or around are called neutral. The alkaline proteases have their $\mathrm{pH}$ optimum in the range of 8 to 11(Rao et al., 1998). Fungal proteases have a wide $\mathrm{pH}$ rang 4-11 (Rao et al., 1998). For example, Aspergillus oryzae produces acid, neutral and alkaline proteases (Nirmal et al., 2011).Proteases produced commonly by filamentous fungi belong to Aspergillus, Rhizopus and Penicillum genera (Souza et al., 2015). The ability of many species of Aspergillus and other genera to produce proteases is well known, therefore, this study was subjected for detection of the fungal recovery rate of soil origin in Golbasi city and Gazi University, Ankara Governorate, Turkeyand for molecularly identification of the recovered isolates. In addition to the proteolytic activity of the isolated Aspergillus strains was evaluated by different method using two types of agar media at same time as a good trial.

\section{Materials and Methods}

\section{Sample collection and fungal strain isolation}

Twenty soil samples were collected in a sterile container from different districts of Golbasi city and Gazi University in Ankara Governorate. For fungal isolation, the collected soil samples were subjected for double fold serially dilutions in sterile distilled water and plated onto Potato Dextrose Agar (PDA) (Himedia M096) plates and the plates were incubated at $30^{\circ} \mathrm{C}$ for 7 days(Raja et al., 2017) then they sub-cultured on Sabouraud-2 \% Dextrose Agar(Oxoid CM0041) plates. The fungal growth were stained by Lactophenol Blue and Safranin and directly examined under the light microscope (Raja et al., 2017). The Aspergillus isolates were morphologically identified based on microscopical examination of conidia and conidiphore, pigment properties of the colonies on PDA and the typical characteristic morphology that was previously proposed according to Pictorial Atlas of Soil and Seed Fungi (Tsuneo Watanabe, 2002).Then those suspected identified fungal isolates by various morphological characteristics were subjected for molecular identification followed by genus-species confirmation.

\section{Molecular identification of the fungal isolates}

For molecular identification of the suspected fungal isolates, they were grown on Malt Extract Agar (MEA)(Merck 1.05398) for 7 days at $25^{\circ} \mathrm{C}$. Genomic DNA were extracted from culture using a microbial DNA extraction kit (Ultraclean Microbial DNA Isolation Kit, Mobio) following the 
manufacturer's protocols, and extracted DNA was stored at $-20{ }^{\circ} \mathrm{C}$. The internal transcribed spacer (ITS) regions of the fungal rDNA genes were amplified by conventional PCR according to Visagie et al., (2014) using the Genus specific primer pairs of V9G-F, TT ACGTCCCTGCCCTTTGTA; LS266-R, GC ATTCCCAAACAACTCGACTC (Samson et al., 2010) and a Veriti ${ }^{\circledR}$ 96-Well Thermal Cycler (Applied Biosystems $\left.{ }^{\circledR}\right)$. Cycling condition reaction was carried at $95^{\circ} \mathrm{C} / 3 \mathrm{~min}$ for primary denaturation followed by 40 cycles of $95^{\circ} \mathrm{C} / 1 \mathrm{~min}, 58^{\circ} \mathrm{C} / 30 \mathrm{sec}$ and 72 ${ }^{\circ} \mathrm{C} / 1 \mathrm{~min}$ for denaturation, annealing, elongation respectively. PCR products were separated by agarose gel electrophoresis (1\% $\mathrm{w} / \mathrm{v}$ in $1 \mathrm{X} \mathrm{TAE})$, visualized by Gel Red staining, cleaned using EXOSAP-IT (Affymetrix, Santa Clara, CA, USA) and used for sequencing. For species confirmation, PCR fragments containing ITS locus were sequenced using a primer pair of ITS1, TCCGTAGGTGAACCTGCGG and ITS4, TCCTCCGCTTATTGATATGC (White et al., 1990). Sequencing reactions were performed with the CEQ ${ }^{\mathrm{TM}}$ DTCS Quick Start Kit (Beckman Coulter, Brea, CA, USA) using the CEQ 8000 Genetic Analysis System. The sequences were allocated GenBank accession numbers and compared with those deposited in the NCBI GenBank Database.

\section{Screening of Aspergillus isolates proteolytic} activity by plate assay method

For screening the biologically active peptides production by the isolated Aspergillus strains, it was carried using two types of agar media as a first application trial (first time). The all identified Aspergillus isolates were spotted onto two agar media including Calcium Caseinate Agar (Merek 1.05409) medium at different $\mathrm{pH}$ of $4.2,5.0,6.6,7.3 \& 8.7$ and Skim Milk Agar (Himedia M763) medium at $\mathrm{pH} 7$ for evaluation their protease-producing ability then they were incubated at $30^{\circ} \mathrm{C}$ for
48 hrs. The clearance zone diameter of the used fungal isolates was measured.The protease producing ability of the isolated strains was selected based on the zone of clearance compared with that of the used known protease producing reference $A$. niger ATCC 16404 strain.

\section{Extraction and detection of Aspergillus proteolytic enzymes}

\section{Obtaining of crude enzyme by semi solid fermentation}

The PDA slants of 7 days old cultures of all isolated Aspergillus strains were separately wetted by $0.1 \%$ Tween- 80 . The spores were scratched by sterile glass wood to obtain homogenous spore suspension of $1 \times 10^{7}$ spore/ml. Ten $\mathrm{g}$ of whole-wheat flour were added to $250 \mathrm{~mL}$ Erlenmeyer flask (repeat two times). One group of them were moistened with $15 \mathrm{ml}$ of distilled water and other were moistened with $15 \mathrm{ml}$ of salted solution [ammonium nitrate 0.5 , potassium dihydrogen phosphate 0.2 , sodium chloride 0.1 and magnesium sulphate $0.1(\mathrm{~g} / 100 \mathrm{ml})]$. The flasks were sterilized, at $121^{\circ} \mathrm{C}$, cooled, inoculated by a one $\mathrm{ml}$ of spore suspension and incubated at $30^{\circ} \mathrm{C}$ for $96 \mathrm{hrs}$. After incubation, $75 \mathrm{ml}$ of distilled water was added to the flasks and shaken on rotary shaker for one hour at $180 \mathrm{rpm}$. (Ikram-ul-Haq, 2003). After filteration and centrifugation $9000 \mathrm{~g}$ at $4^{\circ} \mathrm{C}$ for $20 \mathrm{~min}$ the supernatant was collected and used as crude enzyme ( two types, one moistened with distilled water and the other with salted solution) (Nagamani et al., 2012).

\section{Detection of enzyme proteolytic activity by well diffusion method}

The proteolytic activity of each isolated $A$. niger strains was qualitatively determined using fungal crude prepared enzyme which obtained after fermentation procedure. The 
well diffusion method was also carried onto two different agar media including Calcium Caseinate Agar at different $\mathrm{pH}$ of 4.2, 5, 6.6, 7.3, and 8.7 and solidified for one hour as well as Skim Milk Agar at $\mathrm{pH} 7$ using two different holes which were punched for each plate. After that, two concentrations of 50 and $100 \mu \mathrm{L}$ of each crude enzyme type which prepared previously from all isolated A. niger strains were separately loaded into the holes. The plates were incubated for $24 \mathrm{hrs}$ at $37^{\circ} \mathrm{C}$. The enzyme proteolytic activity extracted from all strains was determined based on the zone diameter of clearance against two enzyme concentrations (each type)onto agar medium.

\section{Results and Discussion}

\section{Morphological identification}

\section{Cultural characters}

On PDA and SDA medium, the typical characteristic morphology of Aspergillus showed white initial growth of colonies that becoming black later (salt and pepper appearance) in six fungal isolates with reverse turning pale yellow colony colour(Fig 1a) while the other three obtained isolates showed greenish colonies and dark greyish-brown

\section{Microscopic examination of fungal isolates}

The direct microscopical examination of six fungal isolates showed spherical vesicles; smooth and colorless uniseriate conidiophores as shown in Fig (1b) while the rest of the three obtained isolates showed branching or simple conidiophores supporting phialides in brush-like clusters known as penicillium in one isolate and rhizoids with non-sepetated hyphae (sporangiophore is unbranched) suspected to be Rhizopus spp. in two isolates. After cultural and direct microscopical examination of soil samples, nine samples (45
$\%$; 9/20) were positive and showed different fungal colonial appearance. Six of these $(66.7 \% ; 6 / 9)$ positive isolates were suspected to be giving rise to Aspergillus with recovery rate of $30 \%(6 / 20)$; one isolate was suspected to be Penicillum $(5 \% ; 1 / 20)$ and the rest two isolates $(10 \% ; 2 / 20)$ showed colonial and cultural characters of Rhizopus.

\section{Molecular Identification of Fungal isolates}

After molecular identification of the isolated fungal isolates, all of them showed $1500 \mathrm{bp}$ fragment (Fig 2) of the ITS regions of the fungal genus specific rDNA genes. After sequencing, the amplified fragments were allocated in GenBank and compared with those deposited in the NCBI GenBank Database giving rise similarity more than $94 \%$ to A. niger in six isolated strains only gave GenBank accession numbers of GQ229076.1， EU314995.1， GQ229076.1, GQ229076.1, GQ229076.1 and GQ229076.1 representing fungal isolates numbers 1-6 respectively.

\section{Screening of proteolytic activity of fungal strains}

In this study, the clearance of proteolysis was qualitative observed after spotting of strains on two new agar media of calcium caseinate agar and skim milk agar used at first time within different $\mathrm{pH}$ range. The clearance diameter zone range of all A. niger strains isolated from soil on calcium caseinate agar was $3.4-20 \mathrm{~mm}$ at $\mathrm{pH} 7.3$ and on skim milk agar was $10-16 \mathrm{~mm}$ at $\mathrm{pH} 7$. The highest clearance zone at $\mathrm{pH} 5.0,6.6,7.3 \& 8.7$ on calcium caseinate agar was for $A$. niger strain code no. 2 with diameters $10,16,20 \& 14$ $\mathrm{mm}$ respectively (Table 1) while that of reference A. niger strain ATCC 16404 at same $\mathrm{pH}$ on same agar medium was $8,12,14$, $15 \mathrm{~mm}$ respectively (Figure $3 \mathrm{~A} \& \mathrm{~B}$ ). 
The proteolytic activity of Aspergillus niger strains

The proteolysis of crude enzymes that extracted from $A$. niger strains on calcium caseinate agar plates by two concentrations at pH 5 or 6 (moistened with distilled water and salted solution in the fermentation medium) was qualitatively and separately determined. The detected clearance proteolysis zone diameter range of $100 \mu \mathrm{L}$ crude enzyme moistened with salted solution prepared from
A. niger strain; isolate code no. 2 was 1014and 1-2mmat $\mathrm{Ph} 5$ and 6 respectively and it was wider than that of the reference $A$. niger ATCC strain 16404 which was determined to be $1-2 \mathrm{~mm}$ at $\mathrm{pH}$ 6. And the enzyme proteolysis of the reference A. niger ATCC strain 16404 at $\mathrm{pH} 5$ was not showed at all (Fig 4). While the detected clearance zone diameter of enzyme moistened with distilled water as well as $50 \mu \mathrm{L}$ crude enzyme concentration proteolysis was negligible and not increase than $1 \mathrm{~mm}$ around the well.

Table.1 The clearance zone diameters of isolated Aspergillus niger strains on calcium caseinate and skim milk agar

\begin{tabular}{|c|c|c|c|c|c|c|}
\hline \multirow{2}{*}{$\begin{array}{l}\text { Code number of } \boldsymbol{A} \text {. niger } \\
\text { strains }\end{array}$} & \multicolumn{6}{|c|}{ Clearance zone (mm) on } \\
\cline { 2 - 7 } & $\begin{array}{c}\text { Calcium caseinate agar at } \\
\text { different } \mathbf{~ p H * ~}\end{array}$ & \multicolumn{2}{c|}{ Skim milk agar at $\mathbf{p H}^{*}$} \\
\cline { 2 - 7 } & $\mathbf{4 . 2}$ & $\mathbf{5 . 0}$ & $\mathbf{6 . 6}$ & $\mathbf{7 . 3}$ & $\mathbf{8 . 7}$ & $\mathbf{7}$ \\
\hline **Reference strain ATCC 16404 & - & 8 & 12 & 14 & 15 & 12 \\
\hline 1 & - & 4 & 6 & 8 & 4 & 10 \\
\hline 2 & - & 10 & 16 & 20 & 14 & 16 \\
\hline 3 & - & 4 & 4.4 & 6 & - & 12 \\
\hline 4 & - & 3.2 & 2.6 & 4 & - & 14 \\
\hline 5 & - & 3.3 & 2.7 & 4.2 & - & 10 \\
\hline 6 & - & 3.0 & 2.4 & 3.4 & 3.5 & 12 \\
\hline
\end{tabular}

*Means of triplicate readings

**Mean growth pattern of known protease producing strain of A. niger

Means not followed by the same superscripts are significantly different $(\mathrm{p}<0.05)$.

Fig.1 Aspergillus niger isolate code no.2. Colony morphology on PDA (a) and microscopic examination of conidia and conidiphore stained by Lactophenol Blue (b)

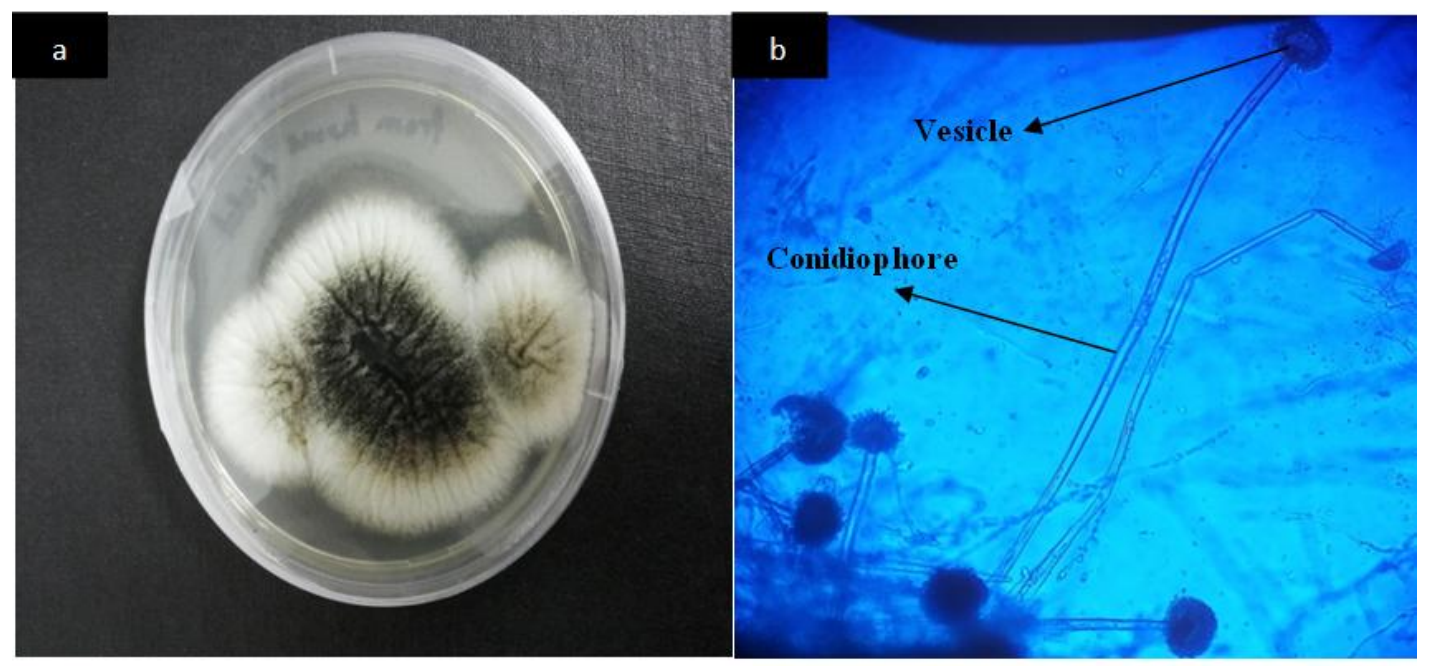


Fig.2 Agarose gel electrophoresis showing typical amplification product of $1500 \mathrm{bp}$ rDNA gene fragments of ITS regions in nine fungal isolates. M: 300-10000 bp Ladder

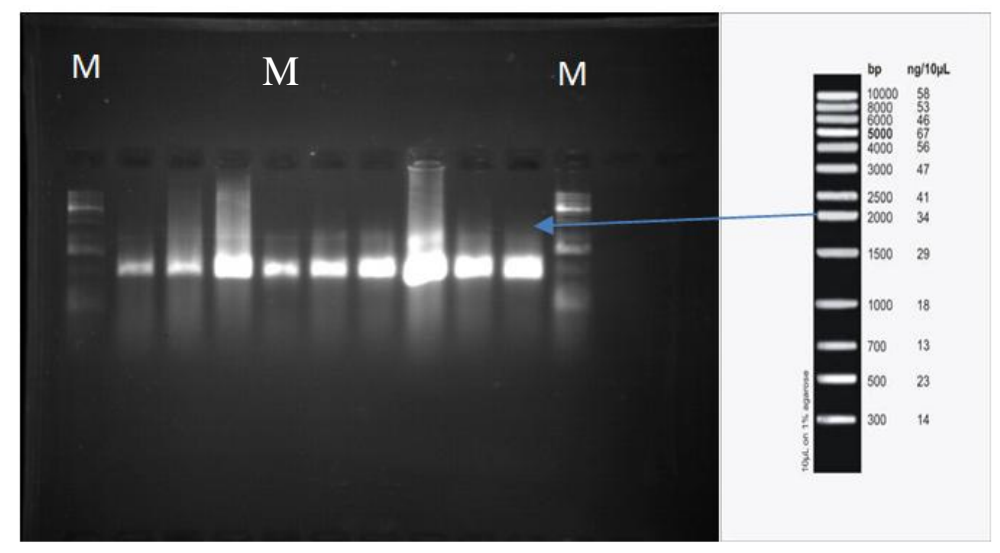

Fig.3 The proteolytic activity of $A$. niiger strains

A) A refrence $A$. niiger ATCC strain 16404; showed the clearance zone on Calcium Caseinate Agar at pH 6.6 (R) on Skim Milk Agar at pH 7 (L)

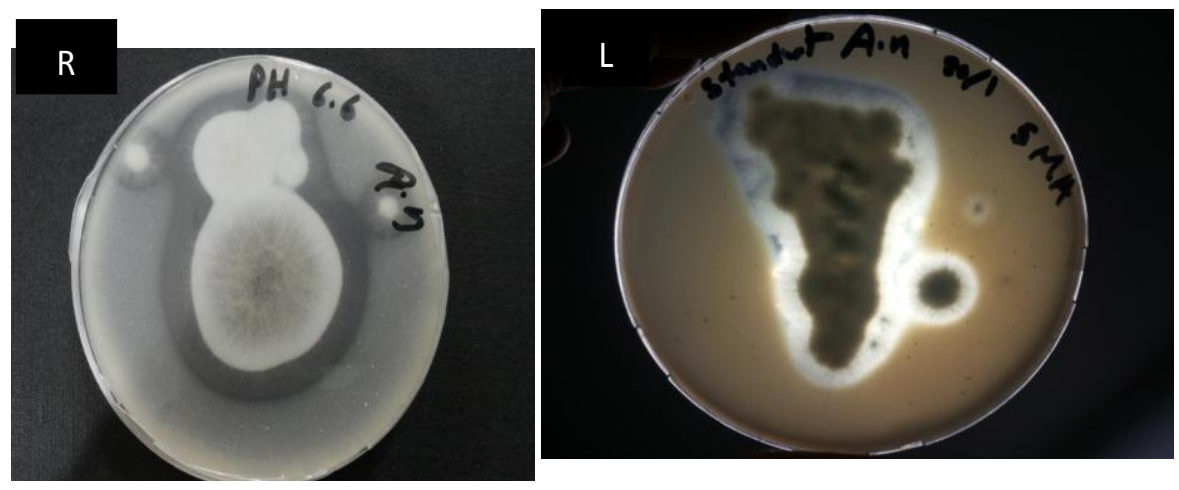

B) The isolated strain of $A$. niger code no.2 showed the clearance zone on Calcium Caseinate Agar at different $\mathrm{pH}(7.3,8.7,6.6)(\mathrm{R})$ and on skim milk agar at $\mathrm{pH} 7(\mathrm{~L})$.

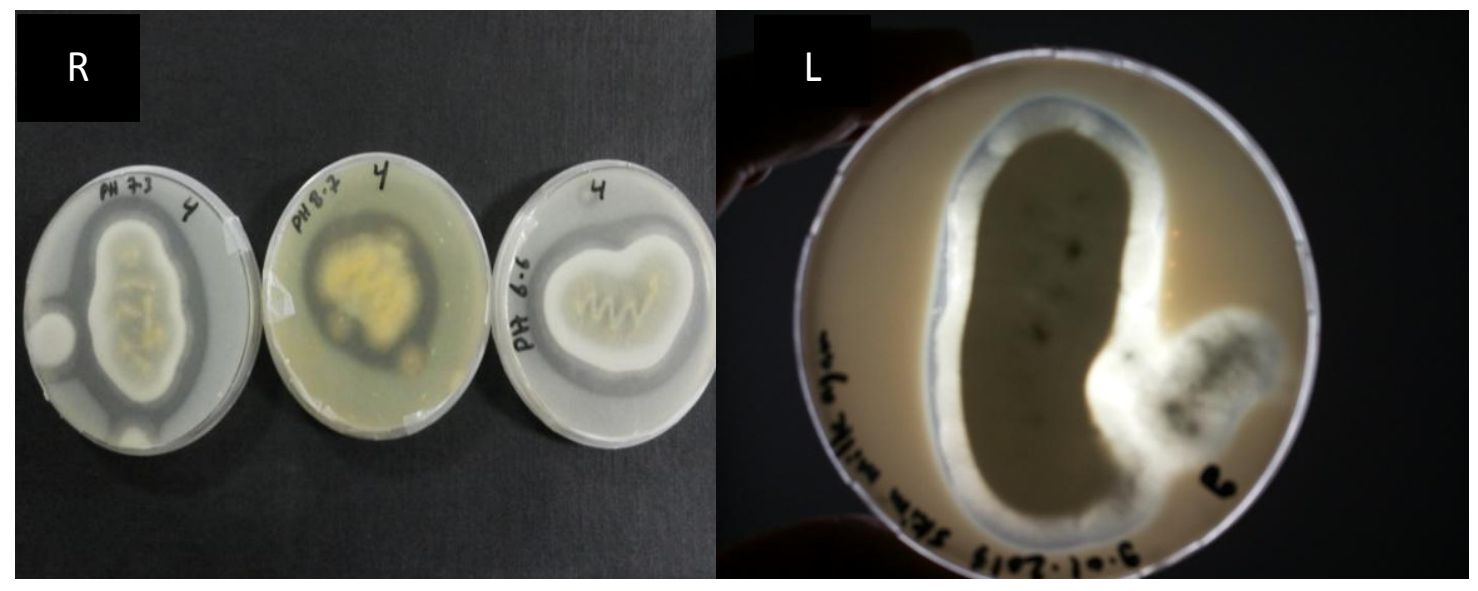


Fig.4 The proteolysis activity of Aspergillus niger crude enzyme 100 цL on Calcium Caseinate Agar moistened with salted solution in the fermentation medium. The clearance zone was 10-14 $\mathrm{mm}$ at $\mathrm{pH} 5$ for $A$. niger strain code no. 2 (a) and 1-2 $\mathrm{mm}$ at $\mathrm{pH} 6$ for reference $A$. niger ATCC 16404 (b)

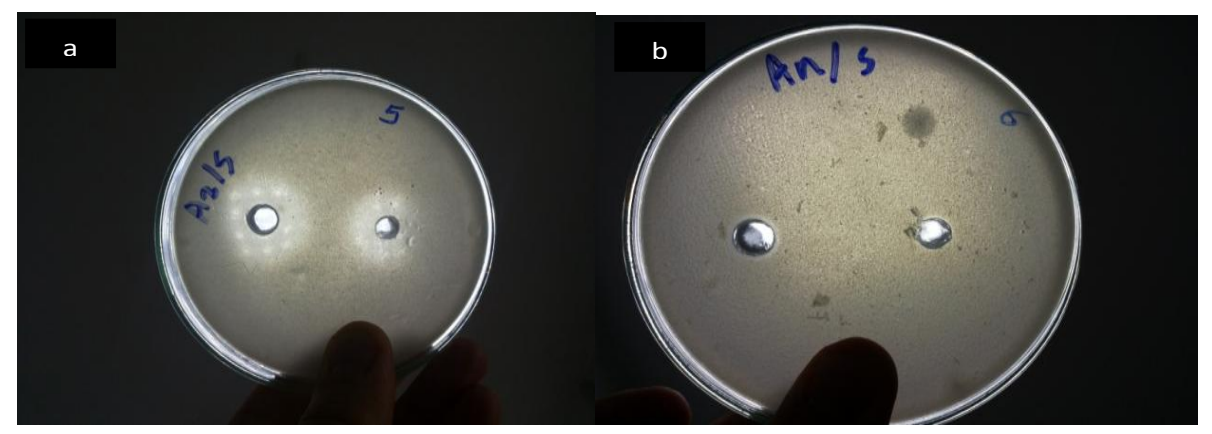

Realy, it is important to note that the morphology of colony, microscopic examination, conidia and conidiophore characteristic were selected as basis for morphologically identification of the fungal strains. Herein, the present study isolated strains belonging to the genus Aspergillus were identified aswhite initial growth of colonies that becoming black later on SDA, dark-brown to black conidia, with uniseriate colorless conidiophores, spherical vesicles and white mycelium, these characteristics were typically identified by Silva et al., (2011). Similar various reports have been published which used the morphological characters as key identifying factors such as Watanabe, (2002); Morya and Yadav (2009) and Bandh, et al., (2012). Other finding proved that during the investigation of 105 fungal colonies, 6 Aspergillus species (A. sparsusi, A. janthinellum, A.ochraceous, A. flavus, $A$. terreus and A. niger) were observed. The maximum fungal species belongs to Deuteromycotina and Aspergillus was dominant among most isolated genera (Sudarkodi et al., 2015).

Molecularly, of nine identified fungal strains showed 1500bp fragment of the ITS regions of the fungal genus specific rDNA genes, six $(66.7 \%)$ were identified as A. niger strains after sequencing with recovery rate of $30 \%$ (6/20). Similar molecular results by Visagie et al., (2014) and Alsohaili and Bani-Hasan (2018) showed that fungal species were isolated and identified at the species level using rDNA ITS sequences comparison and analysis. The eight isolated fungal species were belong to four classes and five of them were Aspergillus as the following: Eurotiomycetes (A. niger, A. tubingensis, and $P$. citrinum); Dothideomycetes (A. alternate, A. gaisen, and A. tenuissima); Sordariomycetes (F. oxysporum) and Mucoromycotina ( $R$. stolonifer) (Alsohailiand Bani-Hasan 2018).

In the present work, production of proteolytic enzymes by fungal isolates was screened by the Plate assay methodusing two types of agar media (including calcium caseinate agar medium at different $\mathrm{pH}$ of $4.2,5.0,6.6,7.3 \&$ 8.7 and skim milk agar medium at $\mathrm{pH} 7$, then they were incubated at $30^{\circ} \mathrm{C}$ for $48 \mathrm{hrs}$ ) as protease substrate good application trial that giving good results. Similarly, the Plate assay method was used for detection of proteolytic activity of fungal isolates by Hankin and Anagnostakis (1975) using gelatin agar medium instead of our used media, in which gelatin is the protein source of that growth medium. The fungal isolates were spot 
inoculated in petridishes with nutrient agar medium supplemented with $1 \%$ gelatin (Peptone, 5g; Beef extract, 3g; NaCl, 5g; Agar, 15g; Distilled water, 1 liter, $\mathrm{pH}$ 6). Then they were incubated at $28 \pm 1^{\circ} \mathrm{C}$ for 3 days. After a week of incubation, gelatin degradation was observed as a clearing zone around fungal colonies. Previously, the clearance zone produced on the agar plate contain casein was related to the amount of protease produced by the fungus (Alane B Vermelho et al., 1996). Recently, the same method as a simple method for qualitative determinations of protease activity but with bromocresol green dye was used by Ponnuswamy Vijayaraghavan et al., (2013).

Herein, the highest protease production was for $A$. niger strain code no. 2 with clearance zone diameters $10,16,20 \& 14 \mathrm{~mm}$ at $\mathrm{pH}$ 5.0, $6.6,7.3 \& 8.7$, respectively on calcium caseinate agar comparing with that of the used reference strain. Nearly to our finding, two fungal species i.e. Aspergillus flavus and Aspergillus niger out of the total six isolates which showed highest proteolysis zone around the colony were proved by Sudarkodi et al,. (2015). On other hand, of the eight, $A$. niger AM07 was considered to be the best amylase producing strain on starch containing nutrient agar but with zone diameter of 7.0 $\mathrm{mm}$ clearing which consider lower than that of our detected diameter (Omemu et al., 2005).

Hence, it seems that $A$. niger strains of soil origin produced acid, neutral and alkalin proteases but the standard $A$. niger strain ATCC 16404 produced neutral and alkaline proteases only. Because the high proteolytic activity upon spot directly on calcium caseinate agar was showed with Aspergillus niger strain code no. 2 at $\mathrm{pH}$ 5.0, 6.6, 7.3, 8.7 while with A. niger strain ATCC 16404 at pH $6.6,7.3,8.7$.

\section{Acknowledgments}

The authors would like to thank the Department of Biology at the Eskisehir Technical University, for providing the necessary equipment for molecular diagnostics of fungal specimens. We also thank the Biology Department at the Gazi University, Microbiology Laboratory, and the Department of Food Engineering, Biotechnology Laboratory at the Middle East Technical University. I also thank Dr. Ahlam Abdel-Aziz Gharib Ibrahime Professor of Microbiology, Microbiology Department, Faculty of Veterinary Medicine, Zagazig University, Egypt for support me in reviewing this article.

\section{References}

Alane Beatriz Vermelho, Maria Nazareth Leal Meirelles, Andréa Lopes et al.(1996) Detection of Extracellular Proteases from Microorganisms on Agar Plates. Mem Inst Oswaldo Cruz, Rio de Janeiro, Vol. 91(6): 755-760.

Alsohaili A. Sand Bani-Hasan M. B (2018). Morphological and Molecular Identification of Fungi Isolated from Different Environmental Sources in the Northern Eastern Desert of Jordan. Jordan Journal of Biological Sciences.11, 3, 329-337.

Anitha TS, Palanivelu P (2013) Purification and characterization of an extracellular keratinolytic protease from a new isolate of Aspergillus parasiticus. Protein Expr Purif 88:214-220.

B.Nagamani, M.V.V Chandana Lakshmi, V.Sridevi and P.Rajani (2012) Production of Protease Sesame Oil Cake by Penicillium Chrysogenum under Solid State Fermentation. ijCEPr Vol.3, NO.2, 137141

Bandh SA, Kamili AN and Ganais BA (2012) Identification of some Aspergillus species isolated from dal lake, Kashmir by traditional approach of morphological observation and culture. Afr. J. Microbial. Res. 6(29): 5824-5827. 
Daiani M. Silva, Luís R. Batista, Elisângela F. Rezende et al., (2011) Identification of fungi the genus Aspergillus section nigri using polyphasic taxonomy. Brazilian Journal of Microbiology42: 761-773.

Hankin L, Anagnostakis SL. Mycologia. 1975; 67: 597. 607.

Ikram-ul-Haq, Hamid Mukhtarm, Sunila Daudi, Sikander Ali and M.A.Qadeer (2003) Production of Proteases by a Locally Isolated Mould Culture under Lab Conditions, Biotechnology, Vol.2 NO.1:3036.

M. Raja, G. Praveena and S. John William (2017) Isolation and Identification of Fungi from Soil in Loyola College Campus, Chennai, India. Int.J.Curr.Microbiol.App.Sci6(2): 1789-1795.

Morya V. K., Kamal and Yadav D (2009) Diversityof indigenously isolated aspergilli from soil of monoculture teak forest. Research Journal of Soil Biology. 1, 3, 7783.

Nirmal N P, Shankar S \& Laxman R S (2011) Fungal proteases: an overview Int. J.Biotech \& Biosci., Vol 1 (1) : pp 1-40.

Omemu, A. M., Akpan, I, Bankole, M. O. and Teniola, O. D. (2005). Hydrolysis of raw tuber starches by amylase of Aspergillus niger AM07 isolated from the soil. African Journal of Biotechnology. 4, 1, 19-25.

Ponnuswamy Vijayaraghavan and Samuel Gnana Prakash Vincent. (2013) A simple method for the detection of protease activity on agar plates using bromocresolgreen dye. J Biochem Tech 4(3): 628-630.

Rao MB, Tanksale AM, Ghatge MS et al., (1998) Molecular and biotechnological aspects of microbial proteases. Microbiol Mol Biol Rev 62:597-635.

Samson RA, Houbraken J, Thrane U, Frisvad JC and Andersen B (2010). Food and Indoor Fungi. CBS-KNAW Fungal Diversity Centre, Utrecht.

Sims GK (2006). Nitrogen Starvation Promotes Biodegradation of N-Heterocyclic Compounds in Soil. Soil Biology \& Biochemistry. 38 (8): 2478-2480.

Souza M. P, Assis Bittencourt L. M, Caprara C. C, Freitas M, Almeida C. P. R, Silveira D, Fonseca M. Y, Filho F. X. E, Junior P. A, Magalhães O. P (2015). A biotechnology perspective of fungal proteases. Brazilian Journal of Microbiology46, 2, 337-346.

Sudarkodi Chandrasekaran, Sundar Sundaram Pillai Kumaresan, Murugan Manavalan (2015). Production and Optimization of Protease by Filamentous Fungus Isolated from Paddy Soil in Thiruvarur District Tamilnadu. Journal of Applied Biology and Biotechnology. 3,06, 066-069.

Tsuneo Watanabe. (2002). Pictorial Atlas of Soil and Seed Fungi, 2nd ed. CRC PRESS Boca Raton London New York Washington, D.C.

Visagie, C.M., Houbraken, J., Frisvad, J.C., Hong, S.B., Klaassen, C.H.W., Perrone, G., et al., (2014). Identification and nomenclature of the genus Penicillium. Studies in Mycology, 78, 343-371.

White TJ, Bruns T, Lee S and Taylor J (1990) Amplification and direct sequencing of fungal ribosomal RNA genes for phylogenetics, in PCR Protocols: A Guide to Methods and Applications, ed. by Innis MA, Gelfand DH, Sninsky JJ and White TJ. Academic Press, New York, NY, pp. 315322.

Zambare V, Nilegaonkar S, Kanekar P (2011) A novel extracellular protease from Pseudomonas aeruginosa MCM B-327: enzyme production and its partial characterization. N Biotechnol 28:173-181.

\section{How to cite this article:}

Wael Shehada, Güven Uraz, Rasime Demirel and Haluk Hamamc1. 2021. Proteolytic Activity of Aspergillus niger Strains Isolated from Soil. Int.J.Curr.Microbiol.App.Sci. 10(02): 67-75. doi: https://doi.org/10.20546/ijcmas.2021.1002.008 